\title{
Mobile Technologies in the Process of Teaching Music Theory
}

\section{Las tecnologías móviles en el proceso de enseñanza de la teoría de la música}

\author{
M.S. Goncharova \\ Herzen State Pedagogical University of Russia, St. Petersburg, Russia \\ ORCID: https://orcid.org/0000-0003-4389-6719

\section{I.B. Gorbunova*} \\ Herzen State Pedagogical University of Russia, St. Petersburg, Russia \\ ORCID: https://orcid.org/0000-0003-3028-692X
}

*Correspondence

Email: gorbunova7575@yandex.ru
Cite as:

Goncharova, M. S., \& Gorbunova, I. B. (2020). Mobile Technologies in the Process of Teaching Music Theory. Propósitos y Representaciones, 8 (SPE3), e705. doi http://dx.doi.org/10.20511/pyr2020.v8nSPE3.705 


\section{Summary}

The article provides teaching materials on the use of mobile technologies in the musictheoretical courses of children's art schools. The use of mobile technologies allows teachers to organize their teaching activities (create a portfolio or a website), create an environment for remote support for learners (virtual classroom with assignments, tests, etc.), change the principles of classwork and homework by means of mobile applications and by making training programs personal and individual, adapted to the needs of each student. Tablets and gadgets have always attracted children, therefore, these familiar devices and the element of game and competition (various music applications) can help music-theoretical courses become much more interesting, draw children's attention and energize them.

Keywords: Mobile Technologies; Music Education; Music Computer Technologies; Digital Educational Technologies.

\section{Resumen}

El artículo ofrece material didáctico sobre el uso de las tecnologías móviles en los cursos teóricos de música de las escuelas de arte para niños. El uso de las tecnologías móviles permite a los profesores organizar sus actividades docentes (crear un portafolio o un sitio web), crear un entorno de apoyo remoto para los alumnos (aula virtual con tareas, exámenes, etc.), cambiar los principios del trabajo en clase y los deberes por medio de aplicaciones móviles y hacer que los programas de formación sean personales e individuales, adaptados a las necesidades de cada alumno. Las tabletas y los aparatos siempre han atraído a los niños, por lo tanto, estos dispositivos familiares y el elemento de juego y competición (diversas aplicaciones musicales) pueden ayudar a que los cursos teóricos de música sean mucho más interesantes, llamen la atención de los niños y los estimulen.

Palabra clave: Tecnologías móviles; educación musical; tecnologías informáticas musicales; tecnologías digitales educativas.

\section{Introduction}

The IT penetration processes transform the environment of a contemporary musician's professional activity, form new educational needs among students, and cause changes in music educators' work. This is due, in particular, to the use of digital educational resources, the widespread adoption of network interaction techniques and methods, and modern music computer technologies (MCT) (Gorbunova, 2019a; Gorbunova \& Hiner, 2019), which have a wide range of capabilities.

The rapid development of digital technologies creates a gap in society between the practice of implementing IT in educational processes and the methodological developments that use them. Nevertheless, digital educational technologies give access to multilateral and dynamic informatization of education. In our article we will consider the use of modern mobile technologies (MT) in education.

Being a part of a dynamically developing IT, MT combine tools and methods that allow to work with digital data through the use of mobile devices (MD) connected to information networks - laptops, smartphones, tablets, and the like.

An important advantage of MT is the ability to provide quick access to cloud-based educational services and resources. For example, the Google Drive service (n.d.) provides a possibility to create a multi-user work environment. The Google Keep service (n.d.) can capture voice input of information both as a text and as an audio recording. Google Presentations (n.d.) 
allow students to create a common project, and Google Forms (n.d.) provide an opportunity for educators to organize online surveys and interactive tests with non-linear questions. Google Sheets (n.d.) can be used as a digital school diary that can be accessed by parents and students. Google Sites (n.d.) allows teachers to create a full-fledged educational website or pedagogical portfolio.

Google services are available to everyone, but educational institutions can also use the services designed to conduct and administer educational activities such as G Suite for Education (n.d.). Its main advantage is that a teacher is able to create a training course, access to which can be obtained on any MD through the Google Classroom application (n.d.). Teachers can administer this service themselves, without the help of a system administrator.

It is obvious that MT can change the quality of interaction between teachers and students, provide access to shared resources and information exchange at any convenient time, which contributes to the introduction of innovative teaching methods, improves the organization of the educational process, and opens up fundamentally new economic opportunities in the education system.

\section{Literature Review}

The theoretical background of teacher training programs for professional activity in IEE with the use of MT was established in the works of such Russian scientists as Berger et al. (2015), Goncharova and Gorbunova (2016, 2018), Gorbunova and Pomazenkova (2015), Gorbunova and Hiner (2014), Gorbunova (2004), Gorbunova et al. (2019a, 2019b), Gorbunova and Goncharova (2019), Gorbunova and Petrova (2019), Gorbunova and Plotnikov (2019); and foreign scientists such as Alieva et al. (2019a, 2019b), Gorbunova and Hiner (2018, 2019), Gorbunova and Hellene (2019), Crawford and Southcott (2017), Gorbunova and Kameris (2019), Chao-Fernandez et al. (2017), Meng (2016), Sosnevas (2018). Practical issues and the possibilities of adult education were widely studied using various technologies, educational firms, workshops, and the like (Berger et al., 2015). Issues of modern pedagogical technologies and principles of teaching with the use of MT were considered in the scientific works of Gorbunova and Kameris (2019), Meng (2016), Sosnevas (2018).

Various aspects of music teachers' professional and advanced training are becoming one of the most popular and discussed topics in Russian pedagogical science (Gorbunova, 2018, 2019b).

In studies revealing the essence and methodology of education with the use of MT, the works by Goncharova and Gorbunova (2016, 2018), Gorbunova and Pomazenkova (2015), Gorbunova (2004), Gorbunova et al. (2019a, 2019b), Alieva et al. (2019a), Gorbunova and Hiner (2018), Gorbunova and Hellene (2019) are of particular importance.

The works of scientists that deal with the specifics of using MT and MCT in the system of modern music and IT education (Gorbunova \& Pomazenkova, 2015; Goncharova \& Gorbunova, 2018; Gorbunova \& Petrova, 2019; Gorbunova \& Zalivadnyi, 2014; Gorbunova \& Plotnikov, 2016), as well as works on approaches based on the studies of the MCT's capabilities as a tool and resource for the implementation of interdisciplinary connections in the cultural scientific and educational space (Gorbunova \& Chibirev, 2019; Gorbunova \& Zalivadny, 2018, 2019) are of great importance for the present study.

\section{Methods and Approaches}

Today, various mobile devices such as tablets become increasingly popular. They offer an infinite number of easily accessible and fascinating Internet services and applications (Toman et al., 2019). Tablet technologies can be used as a completely new, different in form and content 
platform for more entertaining and interactive learning. In this regard, music teachers are faced with an important task of developing practical teaching skills that involve MT.

Unfortunately, not every teacher today owns devices that can help create a high-tech educational environment. This sets fundamentally new tasks for the education system that require new technological solutions, development of pedagogical conditions for their effective use and new approaches to the organization of the educational process in music education.

To realize the benefits of mobile learning, it is necessary to train teachers and educators. Without appropriate training, teachers use technologies only to solve their previous tasks, which does not help transform and improve the teaching process. The understanding of MD's teaching functions and properties will help teachers to actively and confidently use these devices at all educational levels.

MT expand the boundaries of the information educational environment (IEE), while supporting flexible and affordable learning in accordance with the concept of continuous education. MT are capable of influencing all mechanisms of the advanced training process, including formal, informal and spontaneous education. This opens up the possibility for the full development of the teacher's personality due to situational, synchronous, and asynchronous training, compatible with other teaching methods.

Today, there is a need to review the methodological, organizational, psychological, and pedagogical foundations of advanced training educational process that is based on the principles of mobile learning. In this regard, the education system must seek new technological solutions, develop pedagogical conditions for using MT in advanced training and new approaches to organizing educational process.

MT offer a unique opportunity to build such a model of the education system that provides a personalized and professionally oriented educational space.

The success of the mobile learning inclusion depends on the ability to maximize the benefits of MD in practice by all parties of the educational process. To solve these problems and bridge the digital gap between the existing opportunities of MT and their real use in the educational process, it is necessary to prepare teachers for the introduction of MT, create a set of methodological, technological, organizational, and psychological support, provide teachers with access to educational programs and resources through the use of MD, create a favorable IEE with an appropriate moral and psychological atmosphere.

\section{Results and Discussion}

Music teachers today are in the midst of a constant change and improvement of the pedagogical system. In this regard, advanced training is one of the most important stages of continuing professional education, which helps to stay ahead and regulate the endless transformation of the education system.

With the advent of digital-based mobile learning, everything in the educational process is changing: the content of education and the forms of providing it to students, the teaching aids, the types and forms of learning activities, and the relationship between the learning process and student participation.

Every teacher today has to adapt quickly to the changes of educational goals, results, and orientations in choosing the most suitable pedagogical conditions to support all learning processes corresponding to a rapidly changing educational space. 
To solve these problems, it is important to familiarize yourself with the quality and features of the widely spread and popular mobile applications (MA), which are used for ear training.

At the moment, there is a large amount of educational MA aimed at the development of musical literacy, aural skills, and musical thinking. Most of the well-known MA are designed for learning musical notation and the basic elements of the musical language, development of harmonious hearing and sense of rhythm, controlling the accuracy of pitch, expanding aural baggage. In other words, these MA are a training device for developing musical and aural skills.

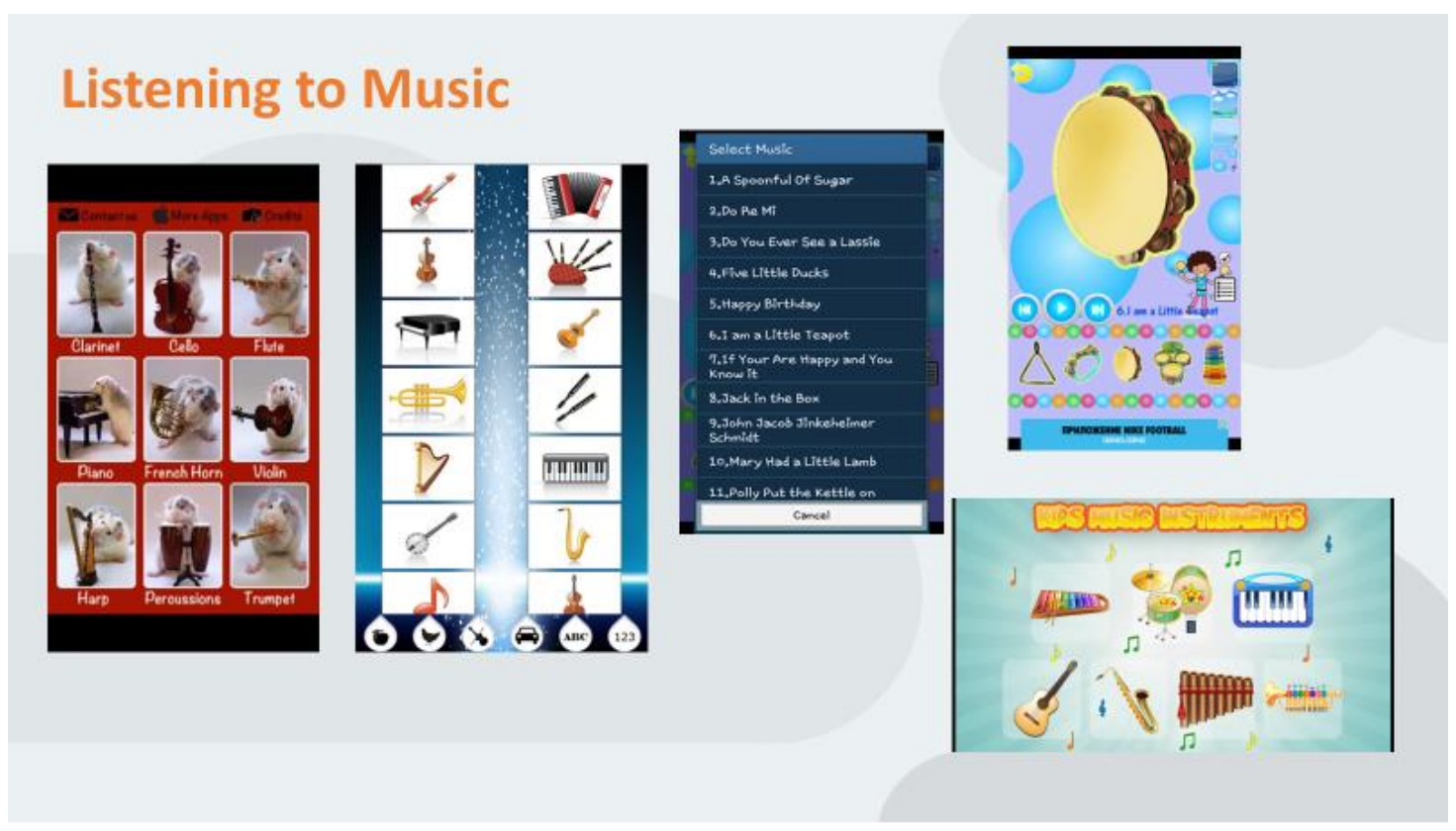

Figure 1. Applications for music listening

Many students use various applications to work with audio-files (for example, to make a ringtone out of a song or to edit various melodies, etc.) or video-files (for video conversion, processing, creating music videos using photos), as well as simple composing applications for music creation in various modern styles (Drum'n'bass, Dubstep, Electronic, Trip Hip Hop, etc.). These applications contain professional studio samples and pads (synthesized sounds) that help create and record one's own improvisations and share them with friends.

The first stage of developing musical abilities is the development of singing skills and elementary intonation. Various lullabies, nursery rhymes, proverbs, and tongue twisters that enrich the vocabulary, develop the articulation apparatus, and phonemic hearing can be used for this purpose. For example, the Nursery Rhymes and Tongue Twisters application (2019) helps students to overcome articulation problems.

The Absolute Hearing application (2018) has a huge number of exercises for ear training: melodic dictations, comparison of intervals, determination of melodic and harmonic intervals, mode, and chords. The application also offers a sufficiently large number of rhythmic patterns with varying difficulty levels that can help develop a sense of rhythm, a wide palette of rare modes (such as Locrian, Dorian, Mixolidian, Blue Mode, Balinese, Egyptian, Hirayoshi, Chinese, Hon Kumoik, Mongolian, Be-Bop, Near East Modes and others), and chords, including non-chords and chords with an embedded second and fourth (sus2 and sus4). A microphone on a tablet allows learners to sing intervals, chords, and modes, which is important for the development of intonation skills. The option of creating individual exercises in the application allows teachers to customize each student's training and difficulty level. All student's achievements can be synchronized with a cloud drive (an account can be created 
through Google Play Games (2020)), which allows teacher to remotely monitor the learning process and results.

The undoubted advantage of this application is that ear training and knowledge testing turns into an exciting process, and this is very welcomed by students. The application offers theoretical material that provides students with the necessary information for performing interactive exercises.

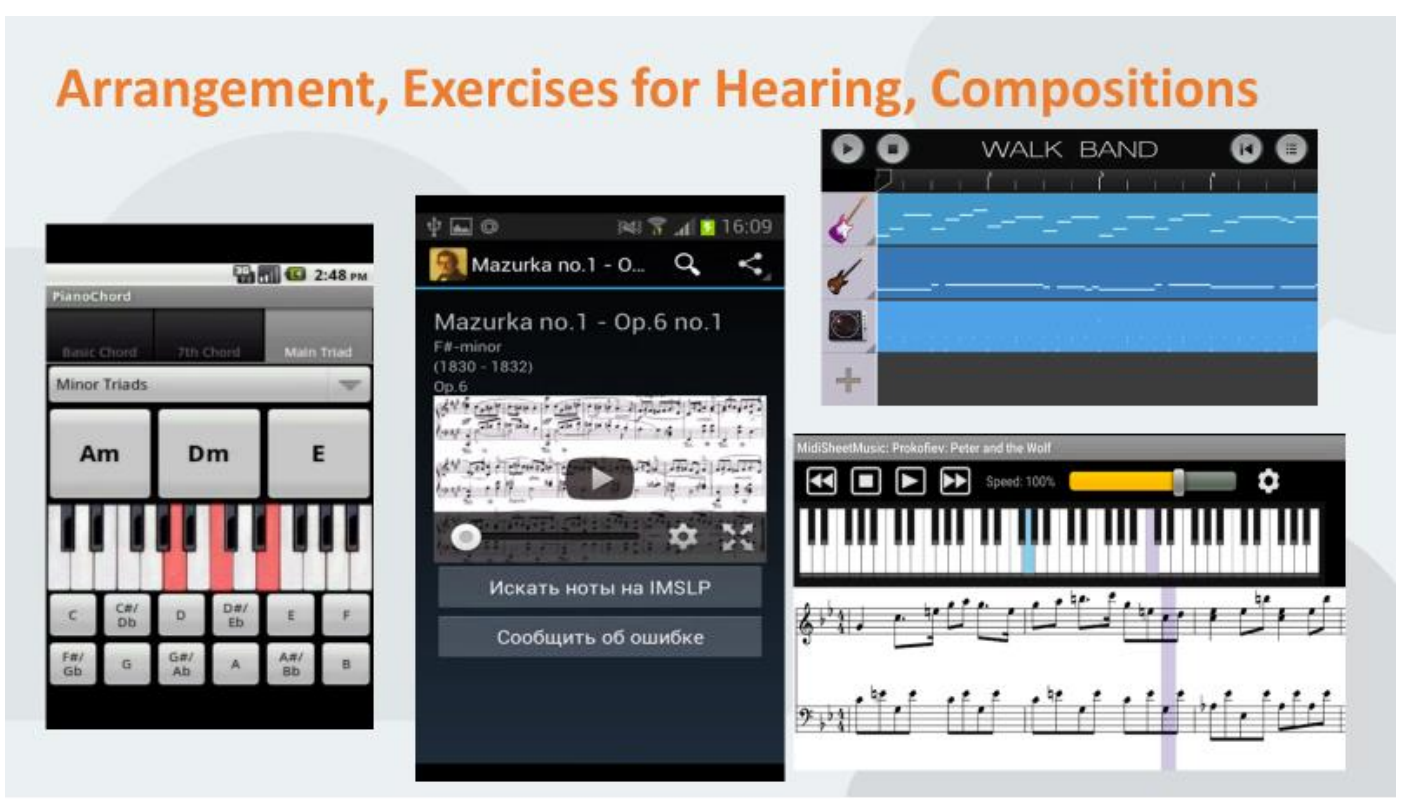

Figure 2. Arrangement, exercises for hearing, composition

The Vocalist Lite application (n.d.) offers a variety of exercises that help develop singing skills and expand vocal range. Students can add and choose melodies, sing them, and receive instant messages on the screen if the wrong note is hit. This application is convenient to use for self-testing, for example, in preparation for a solfeggio test. A tuner application can be very useful in solfeggio classes and in homework - it allows students to "see" the tone that they sing, so that they can sing scales in ascending and descending sequence, intervals, and chords (for example, the Universal Tuner application (2019)).

The Chordbot Lite application (2020) can be used in solfeggio classes to help develop students' creative abilities - with it, students can create an arrangement, for example, from an earlier written chord chain dictation or as a harmonization of the learned melody. This form of learning is especially suitable for wind and string instruments players, who have difficulty playing piano for their creative solfeggio assignments. 


\section{Rhythmic, Melodic, Polyphonic Dictations, Singing the Intervals and Chords, etc.}
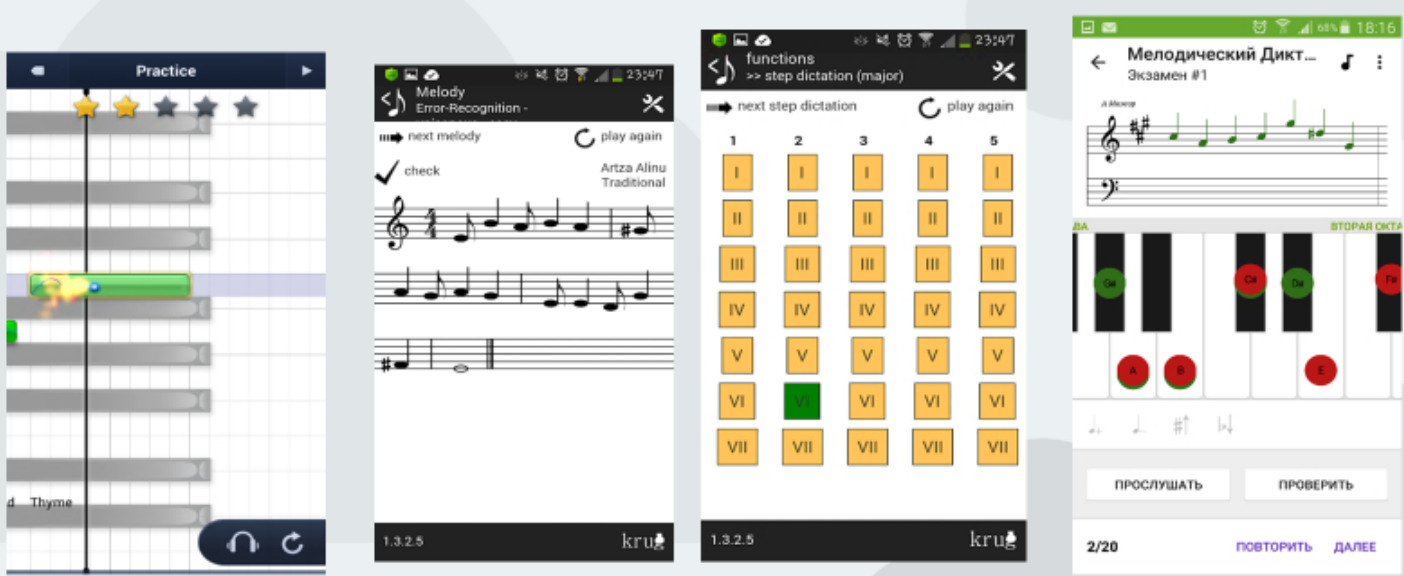

Figure 3. Rhythmic, melodic, polyphonic dictations, singing the intervals and chords, etc.

The standard set of applications on iPad, iPhone, and iPod devices includes GarageBand (2020), which is a digital audio workstation and sequencer for recording and playing multi-channel audio that offers more than a hundred virtual instruments, which can be played with the aid of virtual keyboard or MIDI-keyboard that can be connected to the devices mentioned above.

An important and interesting thing about this application is the Music Lessons section, which allows students to download audio and video piano or guitar lessons. Students can also receive comments and tips about their playing, which can help them quickly improve their playing skills.

Students also independently use a variety of educational applications that help them prepare for different music classes.

\section{Solfeggio, Elementary Theory, Harmony}
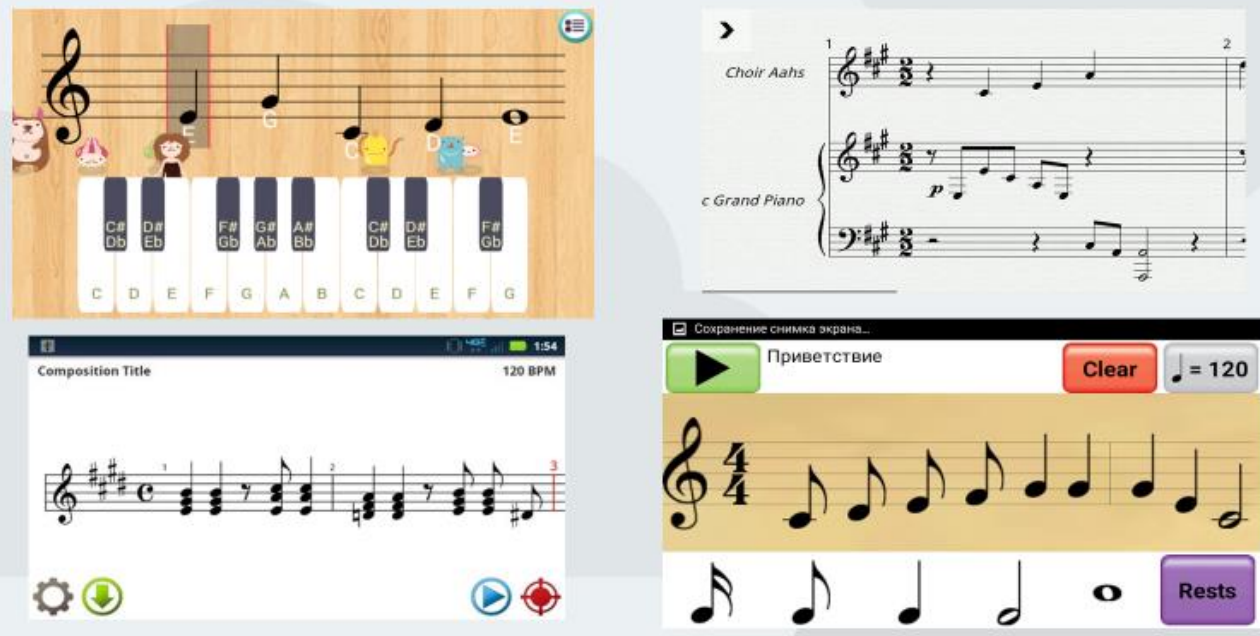

Figure 4. Solfeggio, elementary theory, harmony 
The Walk Band application (2020) for Android and GarageBand (2020) for iOS can be used in solfeggio classes to create an entire orchestra with various instruments which is a great alternative to percussion bands and a good tool for learning new rhythmic patterns. Rhythm is the most important component in the shaping and formation of musical texture, so the variety of exercises would only improve the mastery of rhythm elements. Playing in an ensemble can be considered a comprehensive method for students' development - it creates an opportunity for mutual learning and education and provides a fertile field for creating new musical sound in an atmosphere of cooperation. A well-chosen ensemble repertoire broadens the horizons of children's music knowledge and replenishes the fund of their auditory impressions, which plays an active role in the formation and development of musical thinking and intelligence.

Some applications offer the option of multichannel recording, which opens a huge field for musical creativity and work with musical fragments in different ways. With these applications students can record small scores, rearrange instruments, reduce or combine various music fragments, record their own musical pieces, and improvise. The material is recorded in MIDI format, the created or imported MIDI-files can be edited in the piano roll or using a musical staff. Some applications like Midi Sheet Music (Vaidyanathan, n.d.) allow to import the finished MIDI material into PDF format (for printing). Students can also listen to the created music and see the sounded notes on the music staff and virtual piano keyboard on the screen.

The educational and methodological laboratory "Music Computer Technologies" (2014) of the Russian Herzen State Pedagogical University has developed an advanced training program "Tablet and Cloud Technologies in Modern Music Education" for music teachers. A study guide "Mobile Technologies in Professional Music Education" by Goncharova was published in 2016.

At the initial teaching stage, a tablet is usually used as a replacement for an e-book or a textbook, but its possibilities are truly endless: wireless Internet access opens the door to a huge knowledge base, and students can get remote teacher support (comments, discussion, video calls, etc.). Instant search and information updating, video and audio materials can make an electronic textbook much more interactive. Teachers can create a huge music library for students, as well as various quizzes and tests, which can be assessed through the tablet's Web browser.

Any pedagogical process should be based on accessible teaching aids, visibility and adequate forms of educational interaction. This is easily achieved using tablets and various music applications, which bring learning process to a completely new dimension (it is wellknown that the visual-spatial methods of perceiving musical material are best suited to achieve maximum concentration). For example, motor memory works better with handwriting than with keyboard input. The handwriting recognition function of the NotateMe Now application (2017) provides an option of writing a musical text in the usual way using an electronic pen or a finger. In that case, the tablet imitates a sheet of paper, and the electronic pen not only duplicates the functions of the muscle but also acts as a pen or pencil. And those who are used to a standard computer keyboard can connect it to a tablet via a USB, Bluetooth or Wi-Fi Direct system. 


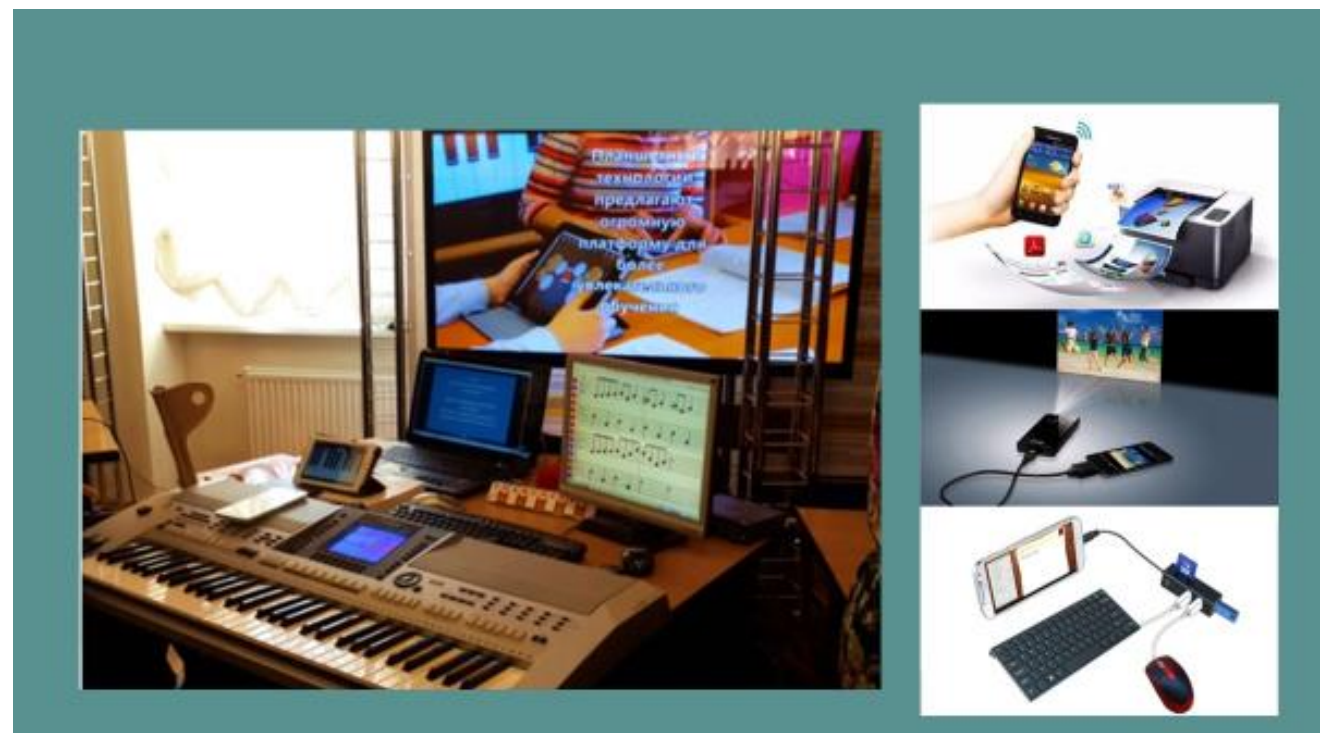

Figure 5. Connecting various devices to a tablet (TV, scanner, video projector, keyboard, mouse)

MIDI-keyboard and other devices can also be connected to the tablet device, for example, external drives, monitors, printers, scanners, video projectors, interactive whiteboards, and the like.
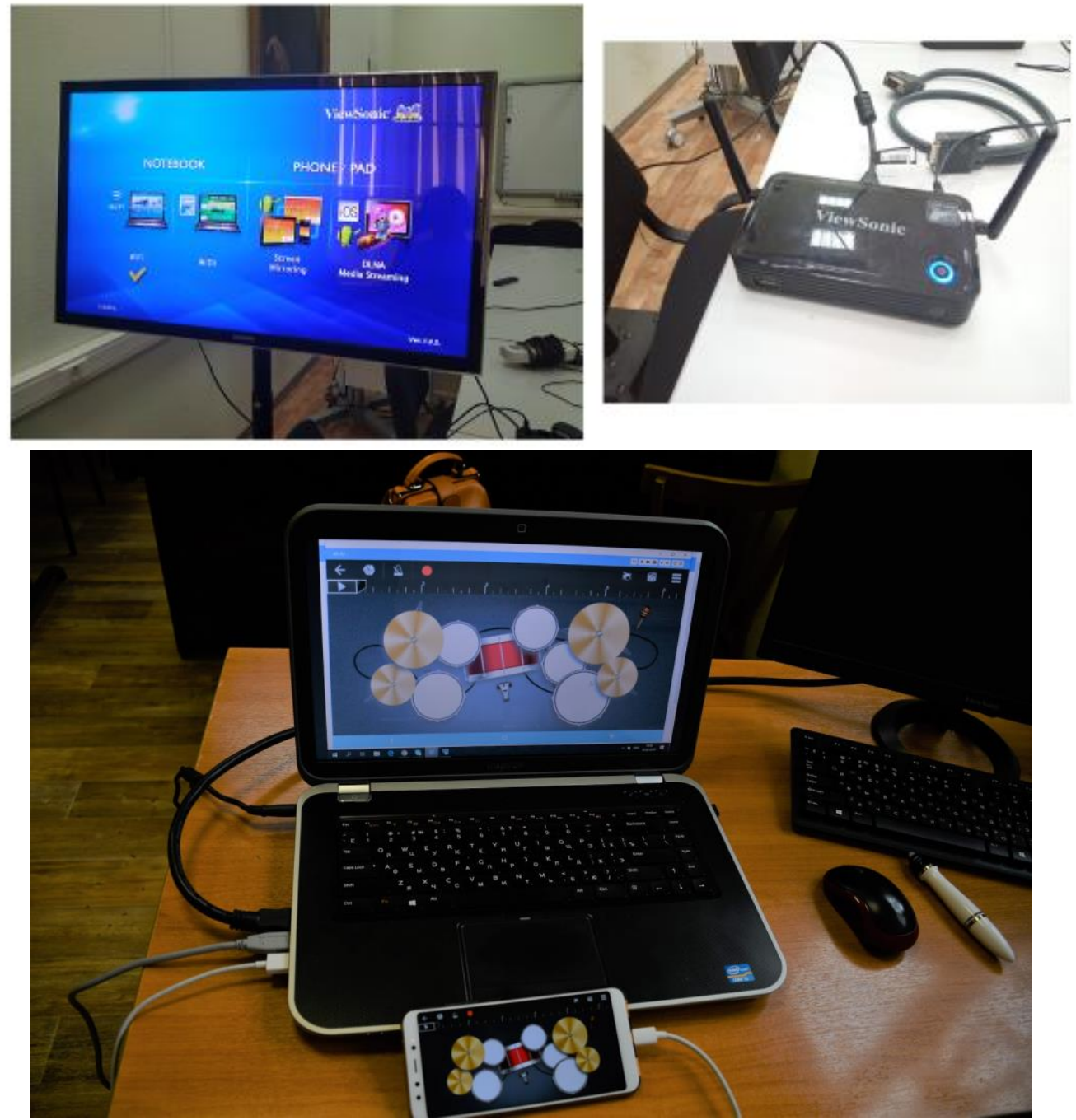

Propósitos y Representaciones 
Figure 6. Connecting the smartphone to the TV using Chromecast

The use of mobile applications in solfeggio classes in children's music schools can be combined with traditional educational program. For example, when studying "Diminished Triads," the following exercises for class- and homework can be used:

\section{Classwork}

1. Using the Perfect Piano application (2020), students are asked to listen to a musical composition while sight-reading the notation and mark the bars, in which the triads are diminished (suggested piece: the theme of the Sea King from the "Sadko" opera by RimskyKorsakov).

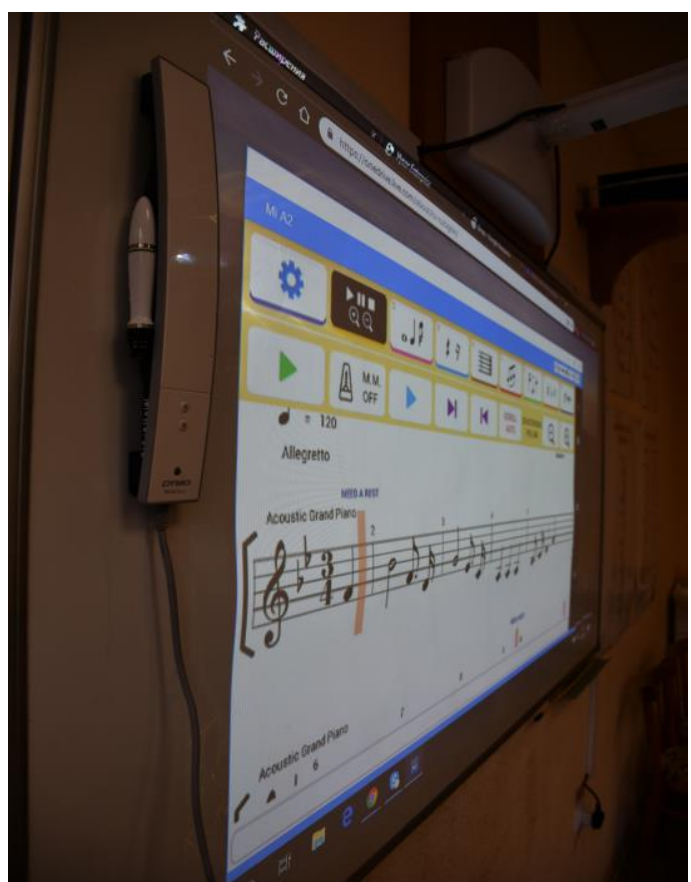

Figure 7. An exercise projected from a smartphone on a whiteboard (Maestro application (2020))

2. Recite the principles of the diminished triad formation (it consists of two minor thirds above the root), and try to resolve a chord using the knowledge of resolving the diminished fifth. The triad is resolved to a tonic third with doubled tonic.

3. Listen to the Minuet from the Schubert's Symphony No. 5, describe its nature, determine genre features and tonality, describe rhythmic features, find the reduced triad, and write it in the Maestro application (2020). Teachers should encourage students to derive the theoretical rule without assistance. Students should compare the structure of a diminished triad on a tonic note and the structure of a diminished fifth on a tonic note. 


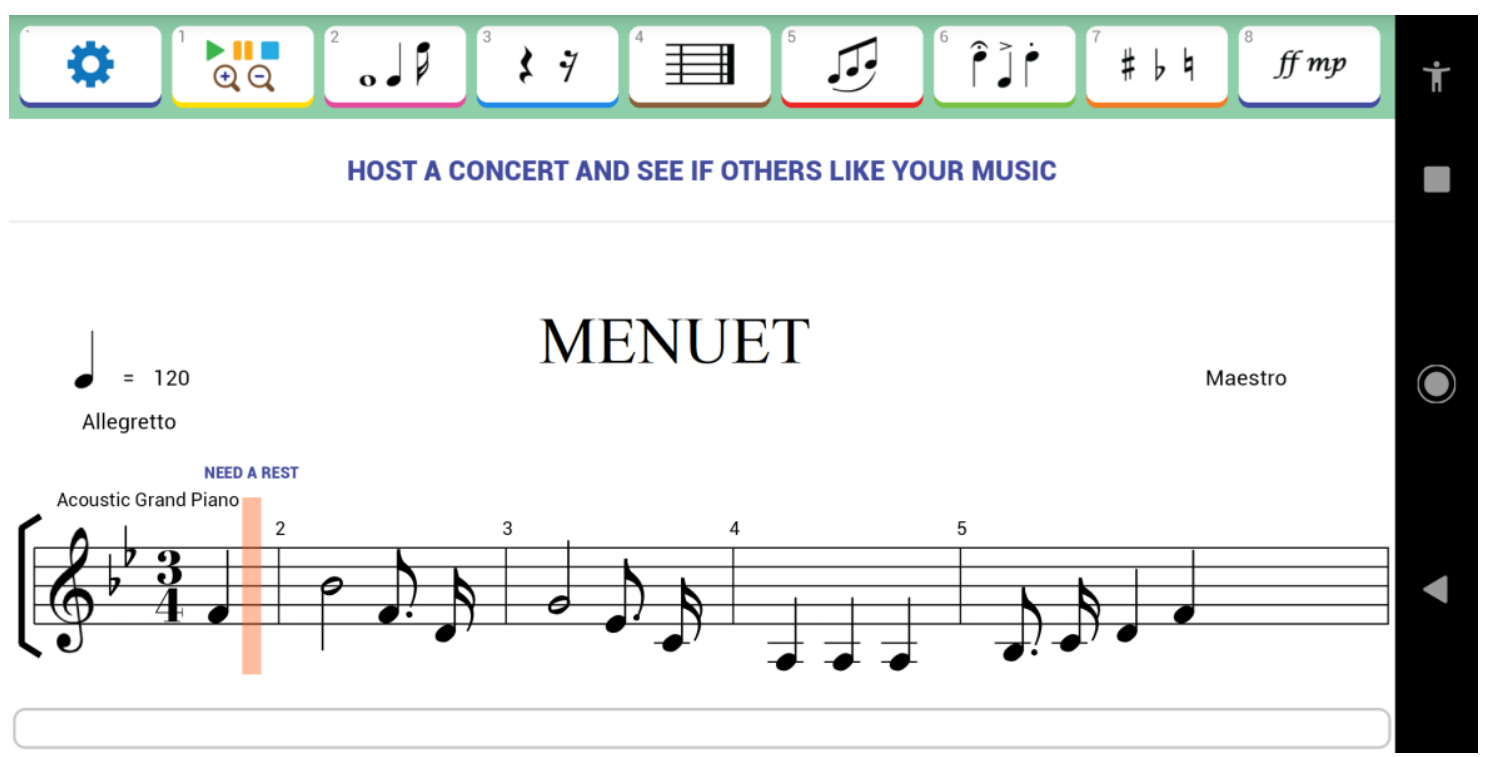

Figure 8. MENUET

4. Write a diminished triad in the Maestro application (2020), resolve it into two tonic notes (major and minor) using Maestro (2020) (individually) and on a whiteboard using the Noteflight application (2020). Sing in chorus the whole composition and the written diminished triad.

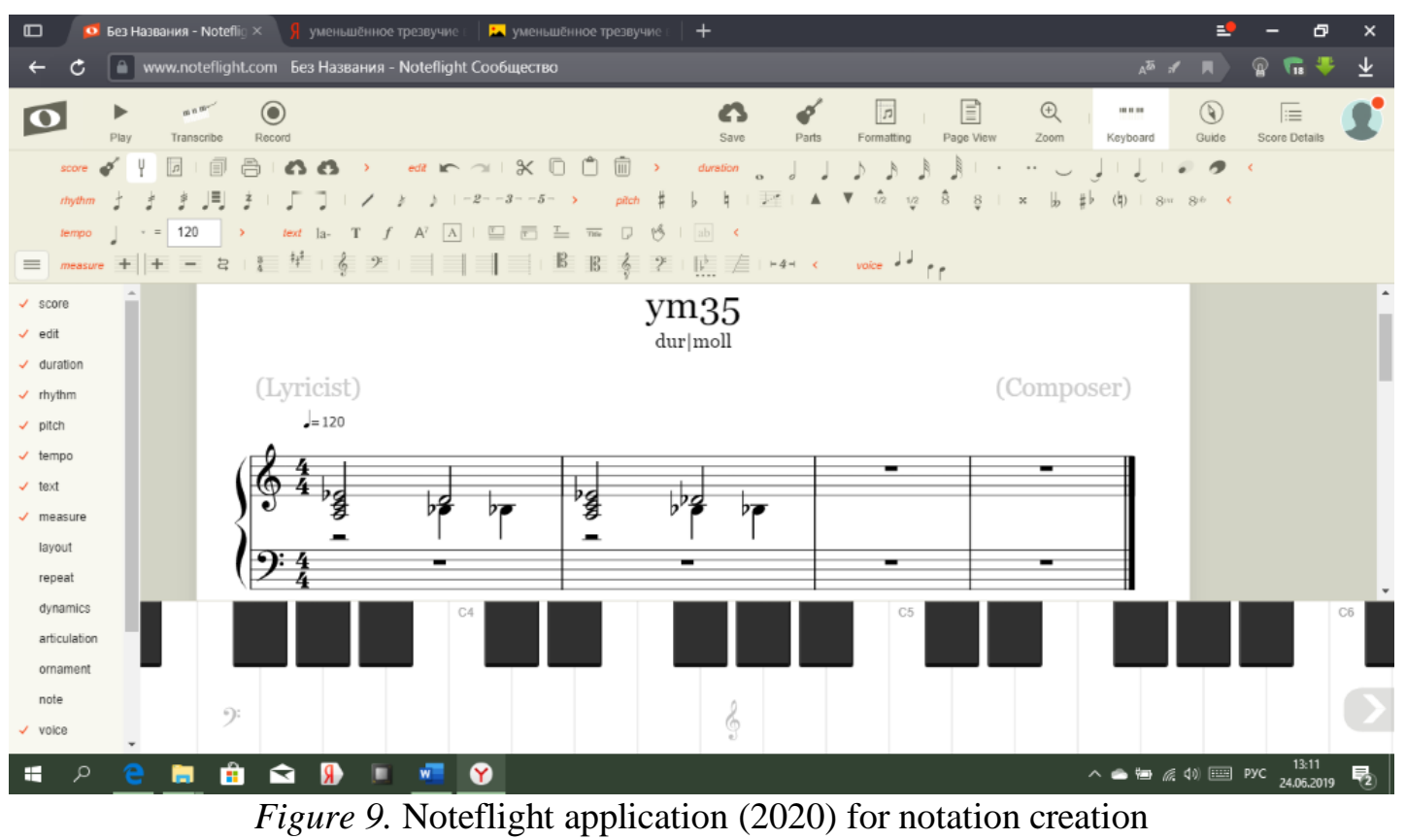

5. Exercises in the Absolute Hearing application (2018): sections Intervals and Chords (singing, ear training, reading). 


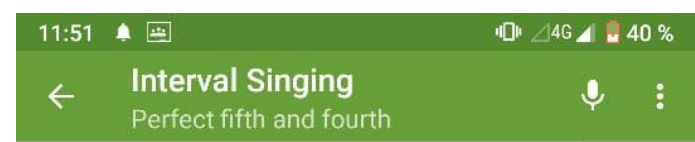

ascending
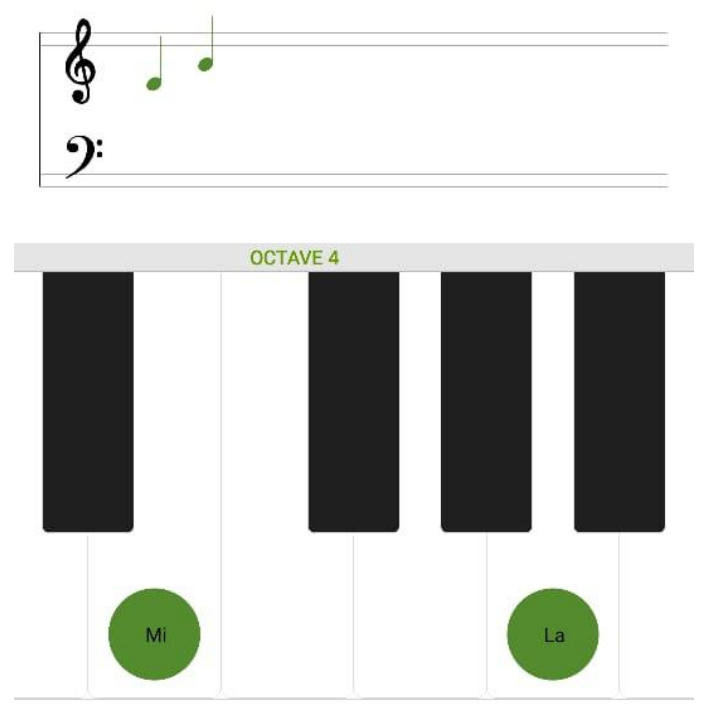

\section{La4}

Precision: -12 cents.

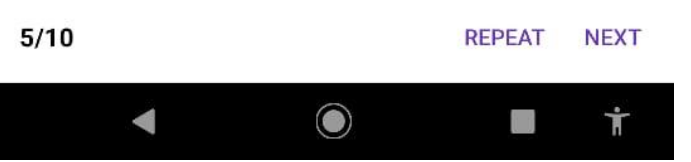

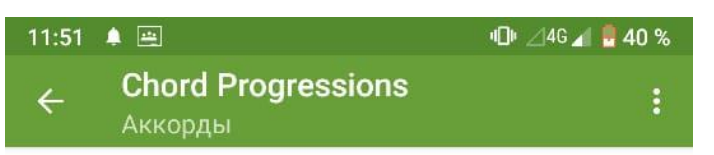
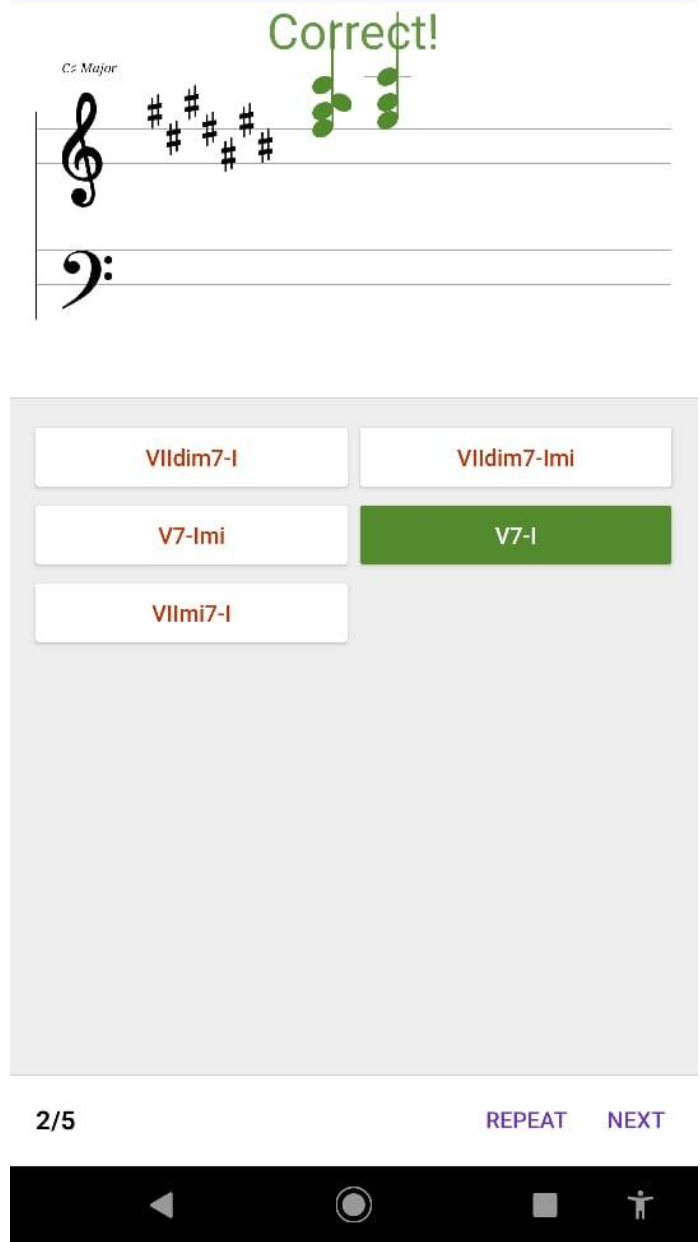

Figure 10. Absolute Hearing 2 application (2018)

The first octave:

a) Intervals section:

- $\quad$ reading intervals: fourth, fifth, tritone, fifth

- $\quad$ ear training: fourth, tritone, fifth

- $\quad$ singing: minor third, major third, perfect fourth, triton, perfect fifth

b) Chords section:

- $\quad$ reading chords, ear training

- $\quad$ singing: major tritone, diminished tritone (10 questions, melodic mode ascending and descending sequence, and harmonic mode)

\section{Homework}

1. Learn the Russian folk song "Along the Street, Along the New" (multimedia mobile edition "Monotonic Solfeggio" for $5^{\text {th }}$ grade by Kalmykov and Fridkin (2004), section "Triplets"). 


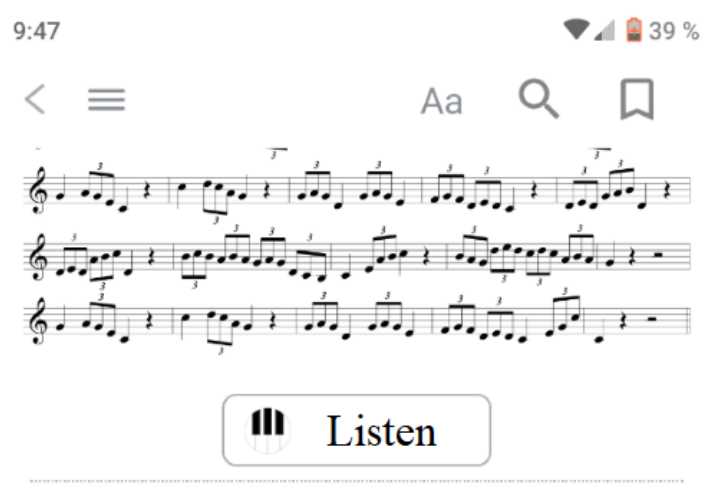

The Russian folk song "Along the Street, Along the New"

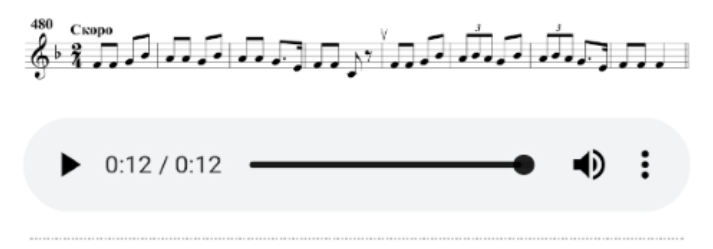

The Russian folk song

"Ah, What is It"

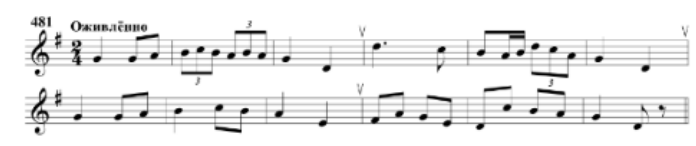

III Listen

V. Muradeli. Song

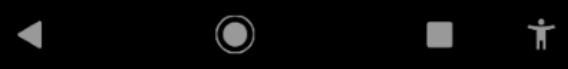

Figure 11. e-Musica application

2. Compose a 4, 6 or 8-bar melody in harmonic minor using the Maestro application (2020), which allows to choose tonality, music instrument, and other options.

3. For advanced students: import composed melody into MIDI-format and (a) open it in the Walk Band application (2020) to record a second voice or to harmonize, add instruments, and rhythmic accompaniment (to strengthen the knowledge of previously studied rhythmic patterns), or (b) open it in the Chordbot Lite application (2020) for auto-arrangement of the chosen harmony (with the use of diminished triad).

4. Record composed melody with accompaniment in the Walk Band application (2020) using the multichannel record option and save it in MP3.

Tablets have several advantages over other devices: relatively small size, which allows users to carry it everywhere; touchscreen interface, silent text input, and headphones option make it possible to work in crowded areas, for example, students of different levels can do individual assignments in the same classroom without disturbing each other.

For a musician, the fact that tablets have a fairly powerful acoustic subsystem (or an optional portable speaker system such as $J B L G o$ ) is especially important - with it, a tablet can 
be used as a sound system or a sound recorder with such options as repeating a certain passage, adjusting the volume, changing the ratio of high and low frequencies, and others. In solfeggio classes tablets can be used for playing scores and certain instrumental parts, changing tones and other variables.

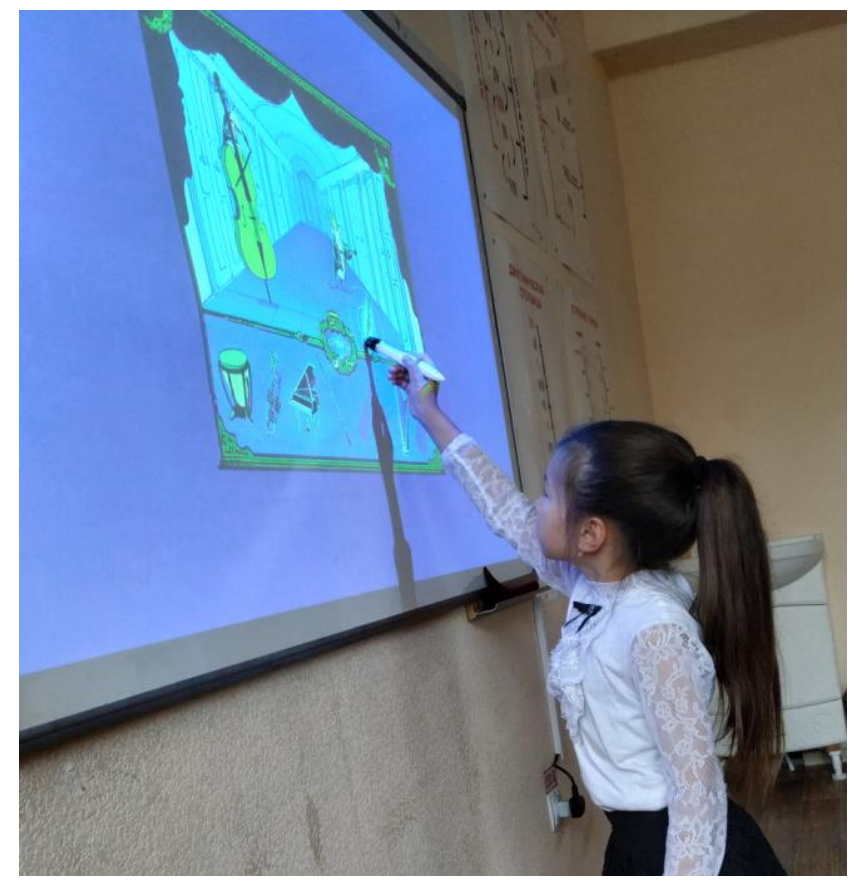

Figure 12. Classwork with an interactive device and a video-projector

In the period from 2012 to 2019, the authors of the article carried out an experimental work, which had five stages: preparatory, establishing, search, forming, and summarizing. At the last stage, the results of the work were being estimated and described, and since the number of recipients continues to increase, the stage appears to be indefinite.

Preparatory stage (2012-2013) included the following steps: systematization of the empirical material; estimation of the problem state (the use of MT by music teachers); sociological and marketing studies to identify the demand for MT among music teachers who seek to improve their professional skills.

Establishing stage (2013-2015) included: questionnaires, interviews, surveys, and screenings, which made it possible to identify the initial level of personal and professional development of music teachers that are preparing to take an advanced training course, to determine the level of their motivation to take this course and the level of their readiness to use MT in the educational process, to identify the complications that may arise when working with MT.

At the forming stage (2015-2017) the authors studied pedagogical conditions for using MT in advanced training courses. The inclusion of MT in the process of advanced training with the aim of teachers' personal and professional development turned out to be productive under the developed set of pedagogical conditions. As a result, a three-level modular advanced training program "Tablet and Cloud Technologies in Professional Musical Education" was developed (Educational and Methodological Laboratory "Music Computer Technologies", 2014). This program includes variant and invariant modules based on the formed complex of pedagogical conditions for the use of MT in advanced training courses. 
At the last stage (2017-present time) the authors continue to summarize and analyze the data, monitor the increasing audience of teachers who join the advanced training courses remotely, correct the developed programs.

During all stages of the work, the accumulated material has been discussed at seminars, master classes, and conferences of various levels dedicated to the process of modernizing the system of professional and general music education, introduction of new educational technologies and programs in the field of continuing education, and the problems of introducing MT and forms of mobile learning into the educational process.

A total of 430 respondents were surveyed. The questionnaire made it possible to determine the level of technological readiness for advanced training using MT (including remote training) and psychological readiness for training using MT. 87\% of respondents are ready for advanced training using digital and mobile technologies, $65 \%$ of them are ready to undergo remote learning, and $44 \%$ expressed a desire to attend courses in person, fearing difficulties in mastering IT/MT and learning remotely.

\section{Conclusion}

It is necessary to reconsider the methodological, organizational, psychological, and pedagogical foundations of advanced training courses development on the basis of the mobile learning principles. To do this, the education system needs to find new technological solutions and approaches to organizing the educational process and develop new pedagogical conditions for use of MT in advanced training.

MT offer a unique opportunity to build a model of the education system that provides a personalized, professionally oriented educational space. Innovations radically affect the emphasis in the content of continuing education, and also shift the vector of development of the continuing education process from professional development to personal-professional development. A professional strategy based on the requirements of society and the state, on personal needs and personality traits necessitates the development of a personalized advanced training program based on MT.

The use of interactive creative exercises based on MT have undeniable effectiveness in music classes. Interactive exercises activate auditory attention, train musical memory and ear, develop taste and observation, figurative and emotional thinking.

The use of mobile devices creates the need for the organization of the educational process with the optimal ratio between the established traditions and new IT in teaching music. That way, the process of knowledge acquisition becomes a process of searching for the necessary information, repetition and drill-work become an exciting creative process, and the study of musical theory (solfeggio, musical literature, harmony, analysis of musical forms, music listening, etc.) becomes one of the methods of modern music communication.

\section{References}

Absolute Hearing. (2018). [https://absolutehearing.ca/] [Accessed on 13 March, 2020].

Alieva, I. G., Gorbunova, I. B., \& Mezentseva, S. V. (2019a). Music computer technologies as a tool of translation and preserving musical folklore (on the example of the Far East of Russia). Music Scholarship, 1, 140-149.

Alieva, I. G., Gorbunova, I. B., \& Mezentseva, S. V. (2019b). Music computer technologies as a worth-while means of folklore studying, preserving and transmission. Utopia y Praxis Latinoamericana, 24(S6), 118-131.

Berger, N. A., Gorbunova, I. B., \& Yatsentkovskaya, N. A. (2015). General musical education in 21st century schools. The World of Science, Culture, and Education, 6(55), 147-151. 
Chao-Fernandez, R., Roman-Garcia, S., \& Chao-Fernandez, A. (2017). Analysis of the use of ICT through music interactive games as an educational strategy. Procedia - Social and Behavioral Sciences, 237, 576-580.

Chordbot

Lite.

(2020).

[https://play.google.com/store/apps/details?id=com.chordbot.demo.gui\&hl=ru]

[Accessed on 13 March, 2020].

Crawford, R., \& Southcott, J. (2017). Curriculum stasis: The disconnect between music and technology in the Australian curriculum. Technology Pedagogy and Education, 26(3), 347-366.

Educational and Methodological Laboratory "Music Computer Technologies". (2014). Advanced training program "Tablet and Cloud Technologies in Modern Music Education". St. Petersburg: Russian Herzen State Pedagogical University.

GarageBand. (2020). [https://www.apple.com/ru/ios/garageband/] [Accessed on 13 March, 2020].

Goncharova, M. S. (2016). Study guide "Mobile technologies in professional music education".

Goncharova, M. S., \& Gorbunova, I. B. (2016). Tablet (mobile) technology for professional music education. Mediamusic, 6. [http://mediamusic-journal.com/Issues/6_3.html] [Accessed on 13 March, 2020].

Goncharova, M. S., \& Gorbunova, I. B. (2018). Mobile technologies in solfeggio classes: Ear training. The World of Science, Culture, and Education, 5(72), 325-329.

Google Classroom. (n.d.). [https://classroom.google.com/u/0/h] [Accessed on 13 March, 2020].

Google Drive. (n.d.). [https://drive.google.com/drive/u/0/my-drive] [Accessed on 13 March, 2020].

Google Forms. (n.d.). [https://www.google.ru/intl/ru/forms/about/] [Accessed on 13 March, 2020].

Google Keep. (n.d.). [https://www.google.ru/keep/] [Accessed on 13 March, 2020].

Google Play Games. (2020). [https://play.google.com/store/apps/category/GAME] [Accessed on 13 March, 2020].

Google Presentations. (n.d.). [https://www.google.ru/int1/ru/slides/about/] [Accessed on 13 March, 2020].

Google Sheets. (n.d.). [https://www.google.ru/sheets/about/] [Accessed on 13 March, 2020].

Google Sites. (n.d.). [https://sites.google.com/new] [Accessed on 13 March, 2020].

Gorbunova, I. B. (2004). Music computer technologies in general and professional musical education. In I. B. Gorbunova (Ed.), Contemporary Musical Education - 2004: Materials of the International Research and Practical Conference (pp. 52-55). Saint Petersburg: Russian Herzen State Pedagogical University, Saint Petersburg State Conservatory named after Rimsky-Korsakov.

Gorbunova, I. B. (2018). Music computer technologies: Advanced training and professional retaining for music teachers. The World of Science, Culture, and Education, 1(68), 232234.

Gorbunova, I. B. (2019a). Music computer technologies in the perspective of digital humanities, arts, and researches. Opcion, 35(S24), 360-375.

Gorbunova, I. B. (2019b). The concept of music computer pedagogical education in Russia. The World of Science, Culture, and Education, 4(77), 267-275.

Gorbunova, I. B., \& Chibirev, S. V. (2019). Modeling the process of musical creativity in musical instrument digital interface format. Opcion, 35(S22), 392-409.

Gorbunova, I. B., \& Goncharova, M. S. (2019). Music computer technologies: Mobile technology in contemporary musical education. Proceedings of the 19th European International Conference on Literature, Education, Humanities and Social Sciences, 13th Budapest International Conference on Chemical, Agricultural, Environmental and Biological Sciences, 21th Budapest International Conference on Law, Business, Gender and Interdisciplinary Studies, 11-19.

Gorbunova, I. B., Goncharova, M. S., \& Tovpich, I. O. (2019a). Mobile technologies in the development of musical hearing. The 175th International Renewable Energy Storage International Conference, 1-6. 
Gorbunova, I. B., \& Hellene, H. (2019). Musical computer technologies: Musical education in digital age school. The World of Science, Culture, and Education, 1(74), 260-262.

Gorbunova, I. B., \& Hiner, E. (2014). Interactive network technologies of musical education in the digital age school: "Soft Way to Mozart" program. Oryol State University Bulletin. New Social Studies Series, 4(39), 104-109.

Gorbunova, I. B., \& Hiner, H. (2018). Music computer technologies and interactive network systems of learning music. Proceedings of the 190th International Institute of Engineers and Researchers International Conference, 16-21.

Gorbunova, I., \& Hiner, H. (2019). Music computer technologies and interactive systems of education in digital age school. In O. D. Shipunova (Ed.), Proceedings of the International Conference Communicative Strategies of Information Society (pp. 124128). Atlantis Press. doi:10.2991/csis-18.2019.25

Gorbunova, I. B., \& Kameris, A. (2019). Music computer education concept for teachers: Raising the problem. International Journal of Recent Technology and Engineering, 8(2 S4), 913-918.

Gorbunova, I. B., \& Petrova, N. N. (2019). Music computer technologies, supply chain strategy and transformation processes in socio-cultural paradigm of performing art: Using digital button accordion. International Journal of Supply Chain Management, 8(6), 436-445.

Gorbunova, I. B., \& Plotnikov, K. U. (2016). Innovation project "Music computer technologies". Siberian Teacher, 3(106), 74-77.

Gorbunova, I. B., \& Plotnikov, K. Yu. (2019). Music-related educational project for contemporary general music education of schoolchildren. International Journal of Innovation, Creativity and Change, 9(13), 683-699.

Gorbunova, I. B., \& Pomazenkova, M. S. (2015). Music computer and cloud-oriented technologies in the system of contemporary musical education. Scientific Opinion, 3-2, 68-82.

Gorbunova, I. B., Tovpich, I. O., \& Yakimchuk, O. S. (2019b). Metatechnology as a way of integration of information, linguistic and artistic milieux of education in the system of general education with the use of music computer technologies. Proceedings of the 226th International Institute of Engineers and Researchers International Conference, 14.

Gorbunova, I. B., \& Zalivadnyi, M. S. (2014). On the importance of information technology for modern experimental aesthetics (musical-theoretical aspect). In O. D. Shipunova (Ed.), Subcultures and Communicative Strategies of the Information Society. Proceedings of the International Academic Conference (pp. 97-100). Saint Petersburg: Polytechnic University Press.

Gorbunova, I. B., \& Zalivadny, M. S. (2018). The integrative model for the semantic space of music: Perspectives of unifying musicology and musical education. Music Scholarship, 4, 55-64.

Gorbunova, I. B., \& Zalivadny, M. S. (2019). Leonhard Euler's theory of music: Its present-day significance and influence on certain fields of musical thought. Music Scholarship, 3(36), 104-111.

G Suite for Education. (n.d.). [https://edu.google.com/products/gsuite-foreducation/?modal_active=none] [Accessed on 13 March, 2020].

Kalmykov, B., and Fridkin, G. (2004). Monotonic solfeggio. Moscow: Music.

Maestro.

(2020).

[https://play.google.com/store/apps/details?id=com.futuresculptor.maestro\&hl=ru]

[Accessed on 13 March, 2020].

Meng, G. K. (2016). Moving toddlers and parents with MCT in Asia. Contemporary Musical Education - 2016. Proceedings of the 15th International Research and Practical Conference, 137-141.

NotateMe

Now.

[https://play.google.com/store/apps/details?id=com.neuratron.notatemenow\&hl=ru]

[Accessed on 13 March, 2020].

Noteflight. (2020). [https://www.noteflight.com/] [Accessed on 13 March, 2020]. 
Nursery Rhymes and Tongue Twisters. (2019). [https://www.nurseryrhymes.com/tonguetwisters-nursery-rhymes/] [Accessed on 13 March, 2020].

Perfect Piano.

[https://play.google.com/store/apps/details?id=com.gamestar.perfectpiano\&hl=ru] [Accessed on 13 March, 2020].

Sosnevas, S. (2018). Arten der Musikausbildung in Deutschland - Der Blick einer zertifizierten Soft Mozart Klavierlehrerin aus Berlin. Contemporary Musical Education - 2018. Proceedings of the 17th International Research and Practical Conference, 235-238.

Toman, Z. H., Toman, S. H., \& Hazar, M. J. (2019). An in-depth comparison of software frameworks for developing desktop applications using web technologies. Journal of Southwest Jiaotong University, 54(4). doi:10.35741/issn.0258-2724.54.4.1

Universal Tuner.

[https://play.google.com/store/apps/details?id=ru.aterlux.guitartuner\&hl=ru] [Accessed on 13 March, 2020].

Vaidyanathan, M. (n.d.). Midi Sheet Music. [http://midisheetmusic.com/] [Accessed on 13 March, 2020].

Vocalist Lite. (n.d.). [https://vocalist-lite.soft112.com/] [Accessed on 13 March, 2020].

Walk Band.

(2020).

[https://play.google.com/store/apps/details?id=com.gamestar.pianoperfect\&hl=ru] [Accessed on 13 March, 2020]. 